\title{
RELATO TRANSMEDIA VINCULADO A MARCAS: EL PERSONAJE DE BENITO COMO INSTRUMENTO DE BRANDED CONTENT
}

\author{
Transmedia storytelling with brands: Benito character \\ as a branded content tool
}

Esteban Galán

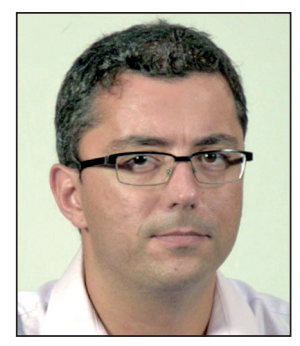

Esteban Galán es profesor del Departamento de Ciencias de la Comunicación de la Universitat Jaume I de Castelló. Es especialista en producción y realización audiovisual (más de 10 años de experiencia trabajando para Canal 9, TVE y la Unión Europea). Su línea de investigación se centra en el estudio de las herramientas digitales en la producción audiovisual y forma parte del grupo de investigación Itaca-UJI. Sus trabajos de investigación son de carácter aplicado y se sustentan en su conocimiento de la industria audiovisual.

http://orcid.org/0000-0001-8718-0937

Universitat Jaume I de Castelló Avda. Vicent Sos Baynat, s/n. 12071 Castellón de la Plana, España egalan@uji.es

\section{Resumen}

La introducción y consolidación en los últimos años de la tecnología digital y de internet ha cambiado el papel del receptor de información, que en este escenario adopta un rol activo. Ante los retos que plantea este cambio, es necesario que las marcas y los creadores audiovisuales trabajen juntos. En este artículo se presenta la utilización de un personaje de ficción, Benito de Cuétara, como vehículo que permite contar historias. Los resultados descritos son el fruto de las cinco sesiones de trabajo realizadas en el marco del / Seminario sobre comunicación transmedia (entre noviembre de 2014 y octubre de 2015) en la Universitat Jaume I (UJI), de Castellón, España, y de la entrevista realizada al equipo que participó en la creación del personaje Benito de Cuétara.

\section{Palabras clave}

Comunicación; Marcas; Contenido de marca; Transmedia; Relato transmedia; Audiovisual; Personajes de ficción; Cultura mediática; Benito de Cuétara.

\begin{abstract}
The introduction and consequent consolidation of information technology and telecommunications in audiovisual stories gives the receiver the ability to change from the traditional role of passive spectator to active user. In this scenario it is necessary that brands and creators work together in order to face the challenges of a new era. The creation of fictional characters, like Benito, can be used as a tool to tell stories and represent a brand (Cuétara). This paper uses the results of five work sessions carried out in the I Seminar of transmedia communication (between November 2014 and October 2015) at the Universitat Jaume I (UJ) de Castellón, Spain and the interview with the creative team that participated in the creation of the character Benito to highlight the benefits of this initiative.
\end{abstract}

\section{Keywords}

Communication; Brands; Branded content; Transmedia; Transmedia storytelling; Audiovisual; Fictional characters; Media cultures; Benito de Cuétara.

Galán, Esteban (2016). "Relato transmedia vinculado a marcas: el personaje de Benito como instrumento de branded content". El profesional de la información, v. 25, n. 6, pp. 915-922. 


\section{Introducción y método}

El propósito de este trabajo es analizar el funcionamiento de las estrategias de creación de contenido transmedia en las que se utiliza el branded content (contenido de marca) para financiar y dotar de identidad al proyecto. A tal efecto se analiza el proceso de creación del personaje Benito, de Cuétara. Actualmente se debe utilizar más de una plataforma para generar contenido y tomar en consideración todas las posibilidades que brinda el relato transmedia.

Para abordar el estudio de caso se ha optado por una metodología cualitativa. Se han utilizado los resultados obtenidos en las cinco sesiones organizadas durante 2014 y 2015 del I Seminario sobre comunicación transmedia en la Universitat Jaume I de Castellón. En ellas se ha trabajado con estudiantes y profesionales de la producción audiovisual y la publicidad aspectos de la comunicación transmedia y las nuevas ventanas de distribución de contenidos. Han participado más de cuatrocientos estudiantes de grado y máster de periodismo, comunicación audiovisual y publicidad que trabajaron junto con realizadores, productores y publicistas especializados en la producción de contenidos transmedia. El valor de este tipo de dinámica de grupo es fundamentalmente exploratorio y permite explicar y contextualizar el objeto de estudio (es especialmente útil en este trabajo por tratarse de un fenómeno de carácter emergente en el que el análisis de los intangibles resulta fundamental). La participación de los estudiantes conjuntamente con el profesorado y los profesionales invitados ha permitido profundizar en las motivaciones, percepciones y actitudes de los consumidores de relatos.

\section{En el escenario transmedia la barrera entre la comunicación interpersonal y la comunicación mediatizada se difumina}

La hipótesis de partida fue si el ecosistema transmedia introducía modificaciones en la gestión del proyecto audiovisual. La dificultad para encontrar financiación y ventanas de distribución para proyectos audiovisuales (Cea-Esteruelas, 2013; Izquierdo-Castillo, 2015) fueron los dos aspectos que se indentificaron como clave:

- en financiación los profesionales resaltaron las estrategias de branded content como la opción más viable y sostenible para una estructura de producción a medio y largo plazo;

- a la hora de distribuir y dar visibilidad al proyecto audiovisual se estableció como uno de los aspectos básicos la utilización de personajes reales o de ficción que pudieran viajar a través de varias plataformas y acompañar así al espectador en su recorrido.

Ante la necesidad de trabajar estrategias de branded content (Scolari, 2013) en las que se utilizara algún personaje con una estrategia multiplataforma, se describió a Benito, de Cuétara, como uno de los ejemplos de éxito en este terreno y se estimó oportuno la profundización en el proceso de creación del personaje, y a tal efecto se entrevistó a su equipo creativo. Pasozebra Producciones, la productora responsable de la creación de Benito, ha transmitido la experiencia y las dificultades que supone la creación de un personaje de ficción de este tipo y además ha facilitado el acceso a la documentación del proceso de trabajo de su creación en 2003. Se eligió una técnica de entrevista en profundidad semiestructurada a partir de tres bloques temáticos:

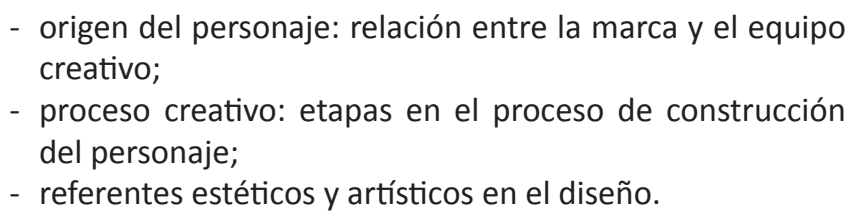

Para seleccionar estos bloques previamente se había realizado un trabajo de observación documental del personaje en las diferentes plataformas lineales y no lineales desde su creación en 2003.

\section{Análisis del proceso de creación de Benito, de Cuétara}

Hay que retroceder al año 2003 para asistir al nacimiento del personaje Benito de Cuétara que hoy todavía goza de gran popularidad entre niños y adolescentes y protagoniza múltiples relatos en varias plataformas.

La productora española Pasozebra Producciones recibió el encargo de crear un personaje vinculado a los Choco flakes de Cuétara con el fin de reposicionarlos. La mascota debía servir para representar la mejora que había experimentado el producto y permitir que los niños y adolescentes se identificaran con ella. El reto era crear un personaje que tuviera los siguientes atributos: transgresor, irreverente, moderno y que pudiera empatizar tanto con el público masculino como con el femenino. La mascota debía servir al mismo tiempo para representar al producto, es decir, su mera presencia debía recordar a los Choco flakes.

Antes de encontrar una inspiración gráfica, los creadores buscaron referentes cinematográficos en los que sustentar su personaje y los encontraron en el personaje que interpreta Marcello Mastroianni en la película Noches blancas (1957) dirigida por Luchino Visconti. La obra es una adap-

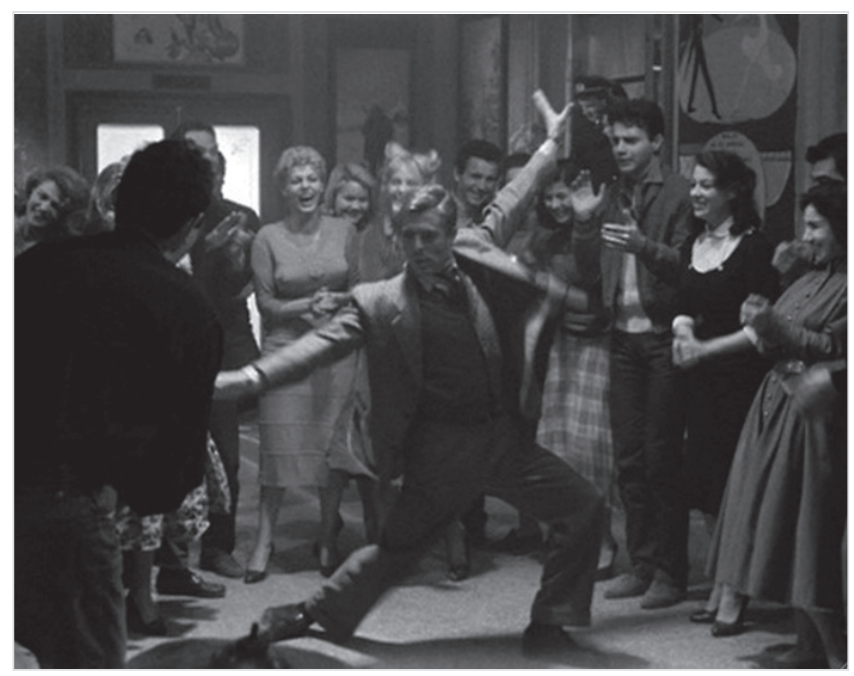

Figura 1. Fotograma del baile del personaje que interpreta Mastroianni. Fuente: Noches blancas (1957) 
tación de una novela de Dostoievski (1848) y el personaje protagonista representa la lucha entre lo real y lo fantástico. El personaje que interpreta Mastroianni inspiró a los creadores de Benito por sus contradicciones y su capacidad para vencer su timidez. La secuencia que sirvió de inspiración para los creadores del personaje se sitúa en un guateque en el que Mastroianni se sobrepone a sus nulas dotes como bailarín y a su carácter introvertido para salir al centro de la pista con unos pasos de baile voluntariamente desacompasados. No sabe bailar pero lo intenta y además lo hace con sinceridad y valentía. Aquí era donde entendían los creadores que debía residir el atractivo del personaje, tenían que buscar un personaje que tuviera aristas, al que se le intuyeran grietas y limitaciones a las que él continuamente se sobrepusiera con una ausencia total de prejuicios y un sentido del humor que le acerca en muchas ocasiones al surrealismo.

Para que la complejidad del personaje llegara al espectador la elección de una voz adecuada era fundamental. Se quería huir intencionadamente de voces que estuvieran asociadas a personajes infantiles. Se buscaba una voz que aportara personalidad a la mascota y que a su vez fuera el vehículo adecuado para transmitir su humor. En esa búsqueda apareció Woody Allen: en la película Balas sobre Broadway (1994) encontraron la inspiración en la voz del personaje de Joe Viterelli, que interpreta a un mafioso.

Teniendo ya los rasgos del personaje y una voz definida faltaba dotar de una imagen que convirtiera a Benito en un personaje fácilmente identificable. Una vez que se tenía definido el concepto de personaje (una mascota transgresora que representara el producto) se decidió buscar referentes visuales en el ámbito de la animación. Se manejaron personajes como Jimmy Neutron, Toy Story, Stuart Little o Wallace \& Gromit. En esta exploración sobre todo se buscaba conocer el tipo de relación que establecían los personajes con los objetos cotidianos y en su caso con los productos o marcas que aparecían en la historia. Una vez seleccionadas las fuentes de inspiración visual se comenzó a realizar bocetos. Los primeros bosquejos se muestran en la figura 2.

Aquellos personajes que podían proporcionar más posibilidades expresivas se abordaron de manera más intensa. Como el personaje tenía que ser capaz de representar el producto se buscaba también que en el diseño estuvieran presentes de manera más o menos explícita los atributos que definen los cereales del desayuno (figuras 3, 4 y 5).

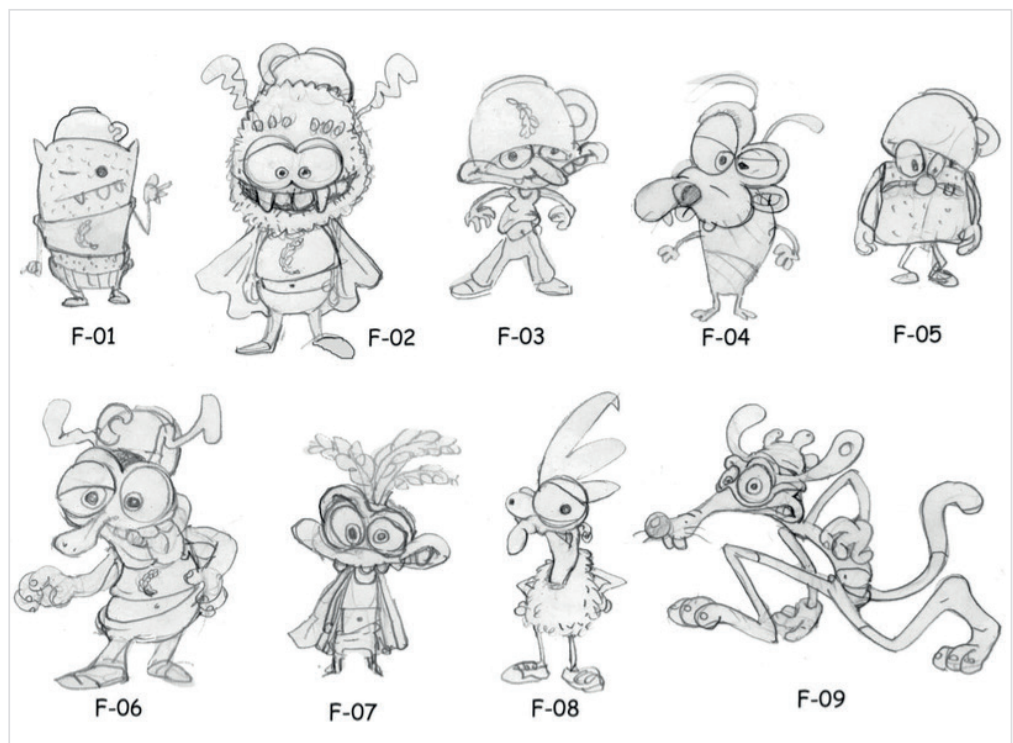

Figura 2. Primeros bosquejos.

Nota: Fuente de éstas y demás ilustraciones de este artículo: Pasozebra Producciones
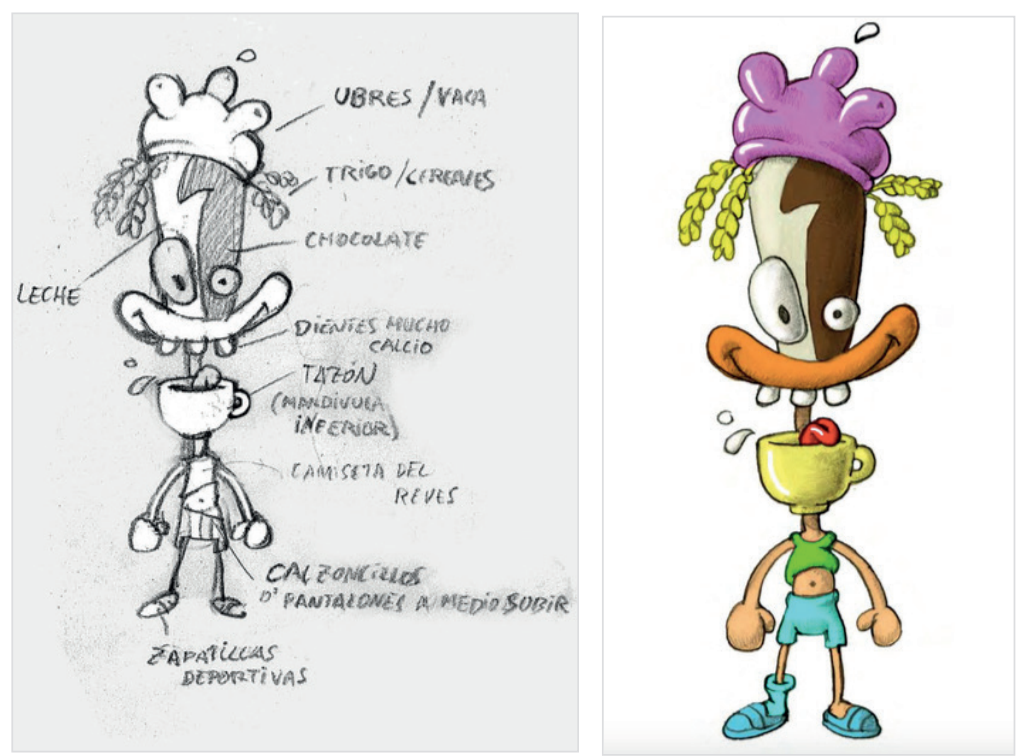

Figuras 3 y 4 . Personajes con atributos de desayuno
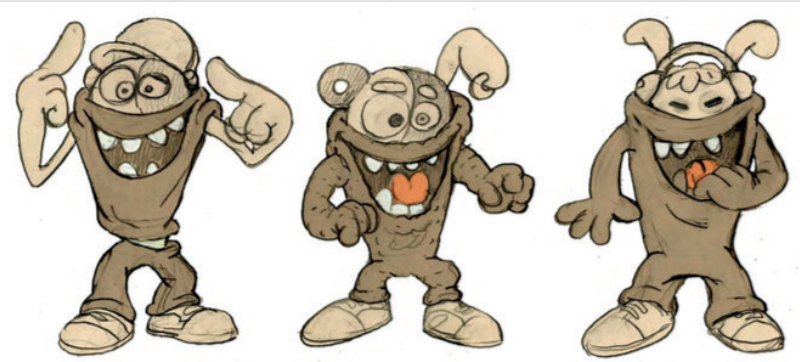

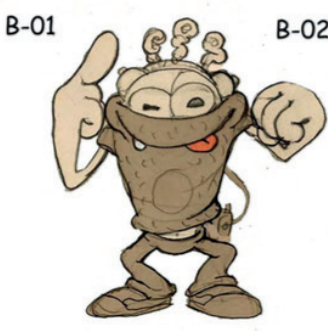

B-04

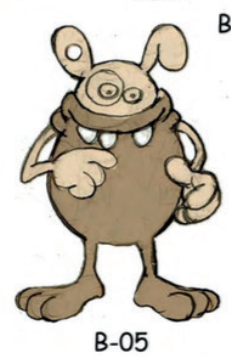

B-03
Figura 5. Personajes con hambre o placer por comer 


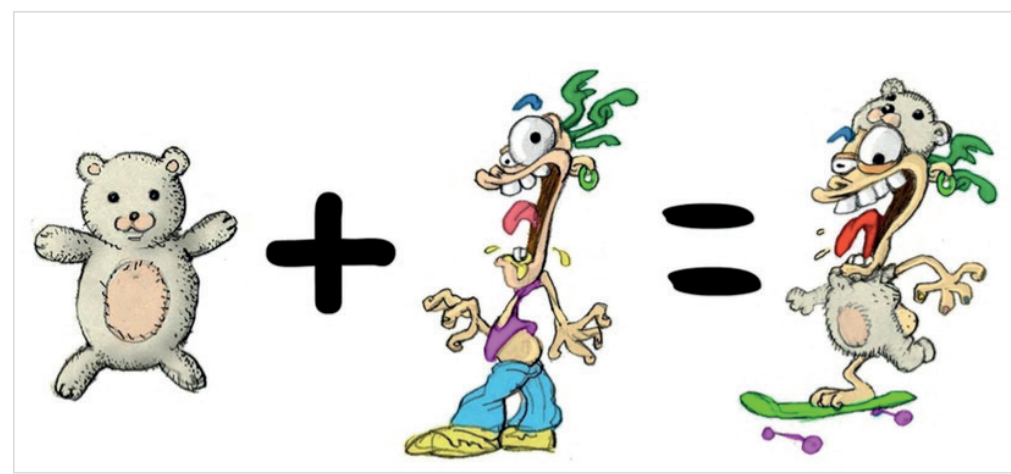

Figura 6. Composición de caracteres

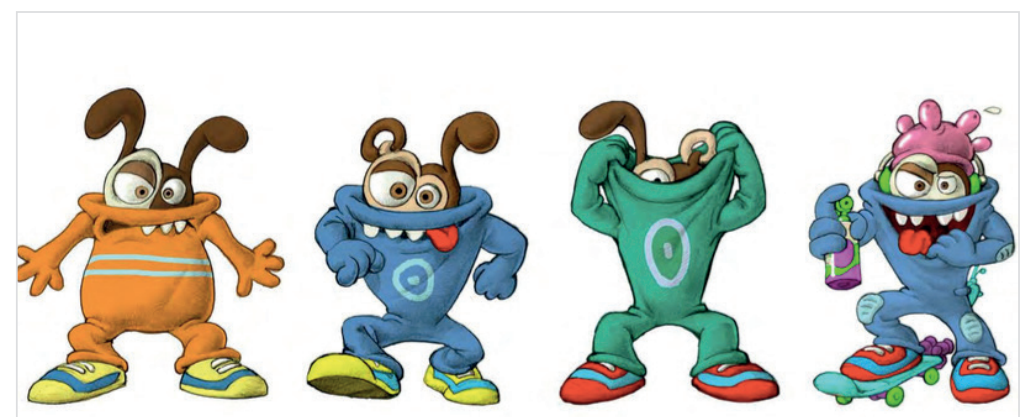

Figura 7. Alzado definitivo en 2D con variaciones

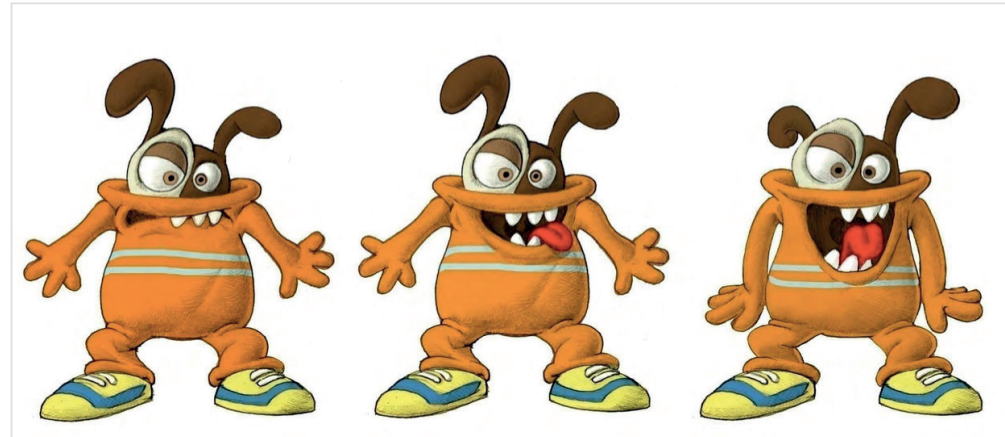

Figura 8. Alzado definitivo en 2D y expresiones previas

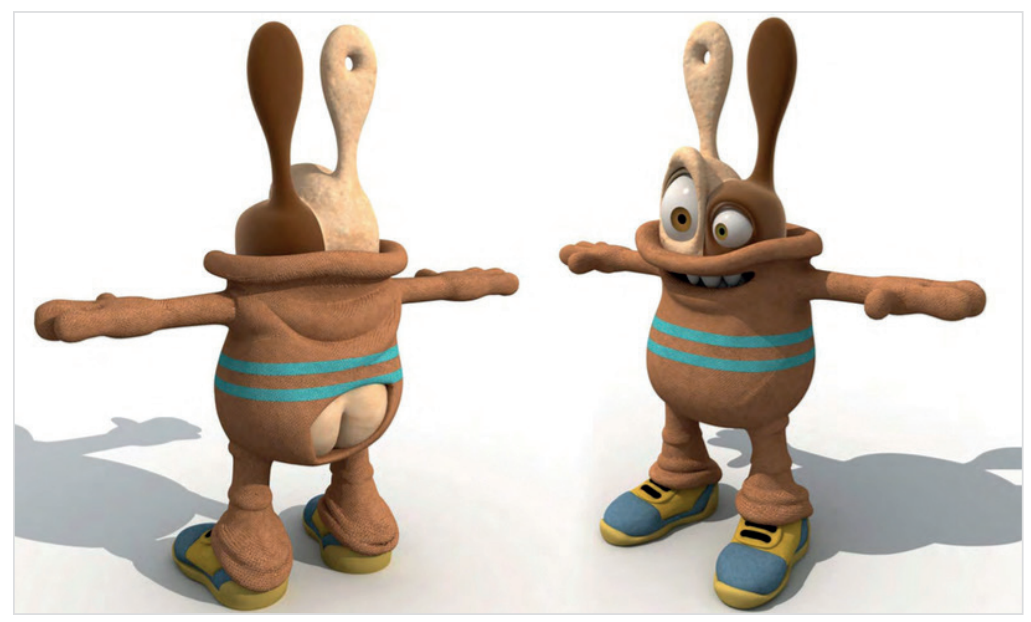

Figura 9. Alzado de Benito y texturizado con iluminación
La creación de un personaje vinculado a una marca en el inicio de un proyecto ofrece igualmente muchas ventajas porque facilita su adaptación a los valores y atributos del producto. También esta etapa es el momento ideal para explorar las diferentes posibilidades gráficas uniendo por ejemplo la imagen de dos personajes (figura 6).

Finalmente después de múltiples pruebas (en este caso el proceso de concepción tuvo una duración de 45 días intensos de trabajo) se procedió a elegir el color y los atributos finales del personaje (figuras 7 y 8 ).

Una vez definidos los atributos básicos del personaje (que le identifican con la marca), su diseño 2D y su color, era el momento de iniciar el proceso de modelado 3D (figura 9).

Terminado el modelado del personaje llegaba el momento de dotarle de vida y para ello era necesario decidir qué expresiones faciales iba a tener, cómo se movería y de qué elementos de atrezzo estaría rodeado. Antes de proceder a la animación es habitual también el trabajo con bocetos (figuras 10, 11 y 12).

La elección del atrezzo que rodeara al personaje era fundamental para que las acciones que protagonizara resultaran verosímiles. Por ello se recurrió a objetos reales que fueron modelados y renderizados para poder interactuar con el mismo.

Una vez que el muñeco ya tiene definidos sus movimientos, diseñadas sus expresiones faciales y está integrado con su entorno cotidiano es el momento de implementar sus posibilidades de merchandising y packaging (figuras 15 y 16).

El personaje supo adaptarse en estos años a las nuevas plataformas que no existían en 2003 cuando fue creado (aplicaciones, YouTube, Facebook). El centro de la estrategia de comunicación continuaba siendo el spot en televisión pero a través de este contenido televisivo y del propio envase del producto se remitía al consumidor a contactar con Benito en varias plataformas. En el envase del producto se animaba a descargar las aplicaciones que se muestran en la tabla 1.

En los envases del producto aparecía un cómic en el que el personaje de manera divertida resolvía una situación curiosa. Al final de cada cómic se invitaba al usuario a seguir nuevas aventuras a través de la web Soy bestial.

http://www.soybestial.com

La web funciona, pero sin la imagen de Benito, lo mismo que en el Facebook corres- 
pondiente, como resultado de una resolución de la Corte de Arbitraje de Madrid que en 2016 declaró cancelado el contrato por el que en 2003 el estudio de animación valenciano Pasozebra cedía los derechos de uso de la mascota Benito a Cuétara. La Corte consideró que el uso de la mascota en aplicaciones y redes sociales -encargadas por Cuétara a diversas productoras- vulneraba dicho contrato, pues tal uso no estaba contemplado en el mismo. En manos ahora de sus creadores originales, la mascota sigue teniendo muchos proyectos por delante y se puede seguir disfrutando de ella bajo el nombre Tikato en su perfil de Facebook (figura 17):

\section{https://goo.gl/hMP9x6}

En su antigua web se ofrecía la oportunidad de jugar en línea a más juegos como los que se muestran en la tabla 2 .

Desde esa web también se brindaba la oportunidad de asistir a contenido disponible en YouTube dividido en cuatro categorías: chorradas, animaladas, trompazos y fenómenos. Estos vídeos cumplían la función de comunicar de manera indirecta los intereses del personaje que a su vez intentaban conectar con los gustos del propio consumidor.

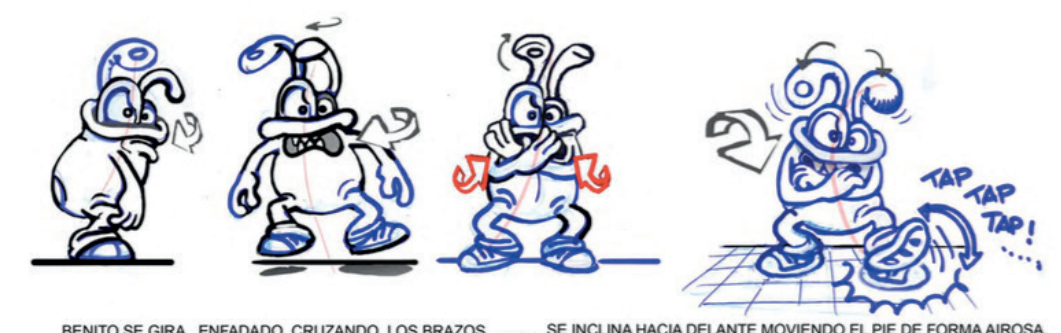

BENITO SE GIRA, ENFADADO, CRUZANDO LOS BRAZOS....... SE INCLINA HACIA DELANTE MOVIENDO EL PIE DE FORMA AIROSA.

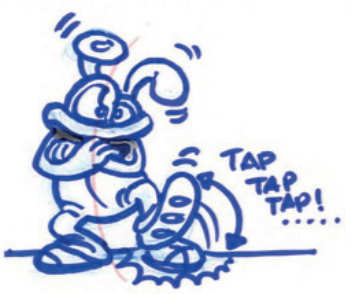

B_BENITO ENFADADO:

BENITO CRUZADO DE BRAZOS,

MOVIENDO UN PIE DE MANERA AIROSA

Figura 10. Benito enfadado

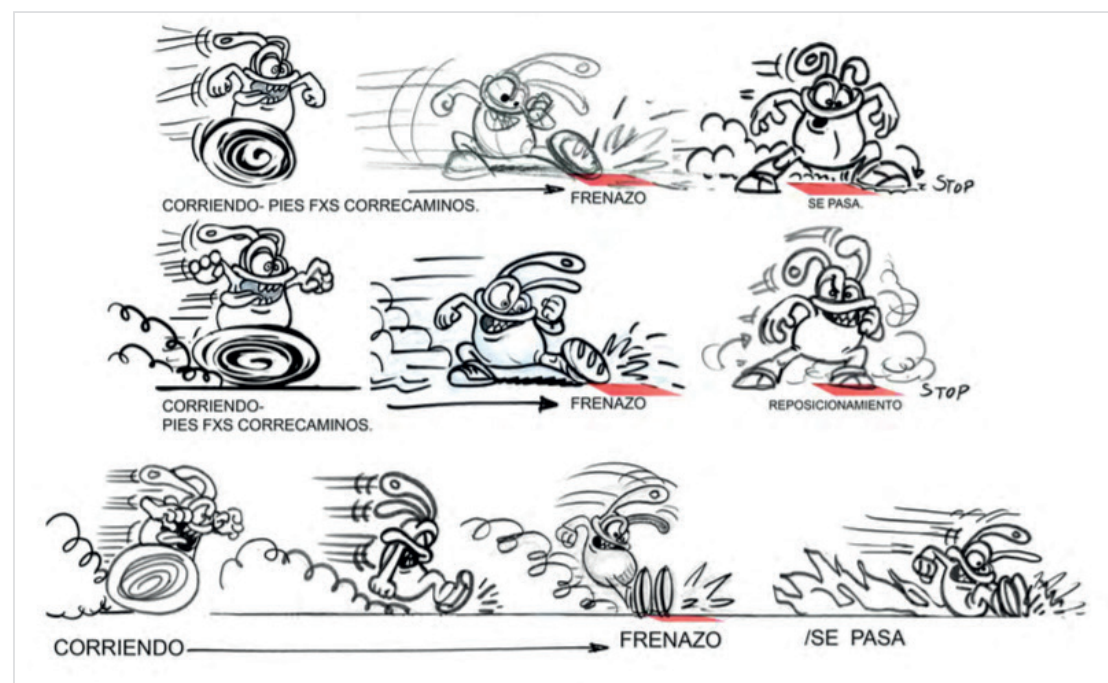

Figura 11. Benito corriendo

Tabla 1. Aplicaciones desarrolladas a partir de Benito

\begin{tabular}{|l|l|l|}
\hline Aplicación & $\begin{array}{l}\text { Descargas } \\
\text { (Google Play) }\end{array}$ & Descripción \\
\hline $\begin{array}{l}\text { Benito } \\
\text { chulito }\end{array}$ & Más de 100.000 & $\begin{array}{l}\text { Ofrecía la posibilidad de grabar } \\
\text { vídeos y compartirlos en las redes. } \\
\text { También resultaba interesante la } \\
\text { opción de poder interactuar con } \\
\text { Benito. }\end{array}$ \\
\hline $\begin{array}{l}\text { Bestial } \\
\text { kombat II }\end{array}$ & Más de 10.000 & $\begin{array}{l}\text { Era un juego donde el protagoni- } \\
\text { sta Benito se batía en duelo con } \\
\text { personajes extraídos de los cuentos } \\
\text { tradicionales pero caracterizados } \\
\text { con atributos más acordes él. }\end{array}$ \\
\hline $\begin{array}{l}\text { Dj soy bestial } \\
\text { pedothron }\end{array}$ & Más de 100.000 & $\begin{array}{l}\text { Ofrecía la posibilidad de interactuar } \\
\text { con una delirante versión del per- } \\
\text { sonaje actuando como disc jokey. }\end{array}$ \\
\hline $\begin{array}{l}\text { Lanza loros } \\
\text { bestiales }\end{array}$ & Más de 10.000 & $\begin{array}{l}\text { Juego muy simple que consistía en } \\
\text { enjaular a un loro de un disparo. }\end{array}$ \\
\hline Más de 10.000 & $\begin{array}{l}\text { Resultaba muy interesante porque } \\
\text { enfocando a la parte de atrás } \\
\text { del envase permitía asistir a un } \\
\text { monólogo del personaje que iba } \\
\text { cambiando en función del tipo de } \\
\text { envase utilizado. }\end{array}$ \\
\hline
\end{tabular}

Tabla 2. Juegos en línea desarrollados a partir de Benito

\begin{tabular}{|l|l|}
\hline Juego en línea & Descripción \\
\hline Bestial basket & $\begin{array}{l}\text { Consistía en realizar lanzamientos a } \\
\text { canasta en un tiempo limitado }\end{array}$ \\
\hline flakes perdidos & $\begin{array}{l}\text { Benito como si fuera el personaje de } \\
\text { Super Mario tenía que ir recuperando } \\
\text { todos los cereales que encontraba en su } \\
\text { camino }\end{array}$ \\
\hline Flakes furious & $\begin{array}{l}\text { Benito se subía a un vehículo y competía } \\
\text { con otros participantes en un circuito } \\
\text { donde intentaba que nadie le adelantara }\end{array}$ \\
\hline Benito's sound machine & $\begin{array}{l}\text { Interesante juego para fomentar la ca- } \\
\text { pacidad de memoria del jugador ya que } \\
\text { era necesario reproducir la secuencia } \\
\text { de sonidos y colores que proponía el } \\
\text { personaje }\end{array}$ \\
\hline Maquea a Benito & $\begin{array}{l}\text { Permitía vestir y dotar al personaje de } \\
\text { los accesorios más disparatados para } \\
\text { provocar un efecto cómico }\end{array}$ \\
\hline El combate más bestia de & $\begin{array}{l}\text { Benito una vez más se batía en duelo } \\
\text { con sus personajes más odiados. Se } \\
\text { ofrecían varios niveles de juego para } \\
\text { adaptarse a las diferentes edades de los } \\
\text { jugadores }\end{array}$ \\
\hline
\end{tabular}



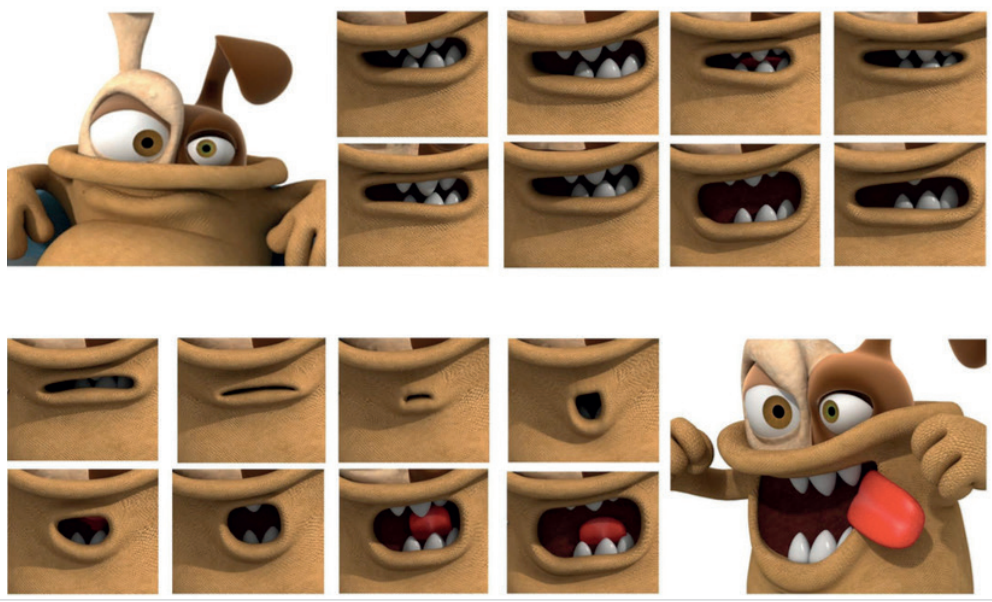

Figura 12. Benito hablando. Proceso de lip sync (sincronía de labios)

Las aplicaciones, juegos y vídeos fomentaban la faceta más divertida de Benito. El humor que caracteriza al personaje tenía su ventana en las pestañas dedicadas a los chistes ( $\mathrm{Hu}$ mor crujiente) y a los monólogos (Mis monólogos bestiales).

\section{Aplicaciones como Monólogos bestiales suponían una experiencia con el person- aje que hacían del desayuno un momen- to divertido}

En la página de los chistes se proponían piezas de 20 segundos con un acompañamiento gráfico que simplicaba la comprensión para los más pequeños. Los monólogos de Benito imitaban la estética y el formato de los programas televisivos de este género y lo presentaban como un humorista descarado. La sección de humor era útil para introducir términos que describían el producto: chocolate, bestial, crujiente, leche, desayuno, etc. Este vocabulario también se encuentra en el envase de los choco flakes.

En la web se ofrecía un contenido adicional relacionado. En la pestaña "Soy famoso en TV" se asistía al visionado de siete spots televisivos con Benito como protagonista. Se caracterizaban por un estilo de realización ágil donde Benito tenía que solventar alguna situación adversa para conseguir su tazón de leche con cereales. En ocasiones también utilizaba estrategias que bordeaban lo violento y/o escatológico [en 2014 recibió una denuncia a través de la web TV infancia

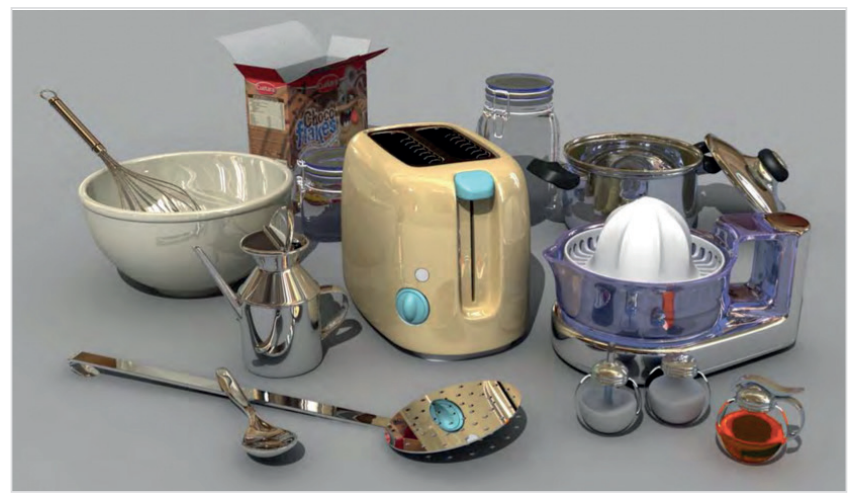

Figura 13. Modelado y render de objetos de cocina que fue desestimada por la Asociación para la Autorregulación Comercial (Autocontrol)]. http://www.tvinfancia.es http://www.autocontrol.es

Se ofrecía asimismo la posibilidad de descargar emoticonos animados, sonidos y felicitaciones de cumpleaños en las que Benito instaba al celebrante a ser bestial en la celebración: poner la música alta, gran cantidad de comida y refrescos muy grandes.

La redacción y el diseño de este tipo de contenidos suponía una nueva oportunidad para vincular al personaje y por tanto a la marca con la rutina diaria del consumidor. Conseguir que un niño desee ser felicitado por Benito era una oportunidad para lograr un vínculo emocional duradero. En el escenario transmedia la barrera entre la comunicación interpersonal y la comunicación mediatizada se difumina cada vez más y ambas esferas interaccionan retroalimentándose mutuamente.

En las dos últimas pestañas de la web se presentaban los productos vinculados a Benito: Flakes bomb, Flakes nocilla, Cachobarra, Choco flakes y Choco flakes callejeros. El lenguaje a la hora de presentar estos productos no se modificaba y se empleaban expresiones coloquiales tales como: brutales, pasada, gorrones, etc.

\section{La creación de un personaje vinculado a una marca en el inicio de un proyecto ofrece muchas ventajas}

Por último, una de las pestañas más significativas era "Más bestial", en la que se proporcionaba una ficha del personaje con sus gustos, antecedentes, personajes con los que se relaciona y álbum de fotos. También en esta sección se presentaba a Benito como alguien que odiaba la Navidad, los gatos y el despertador. El hecho de que durante todas las producciones los creadores se esforzaran en hacer de Beni-

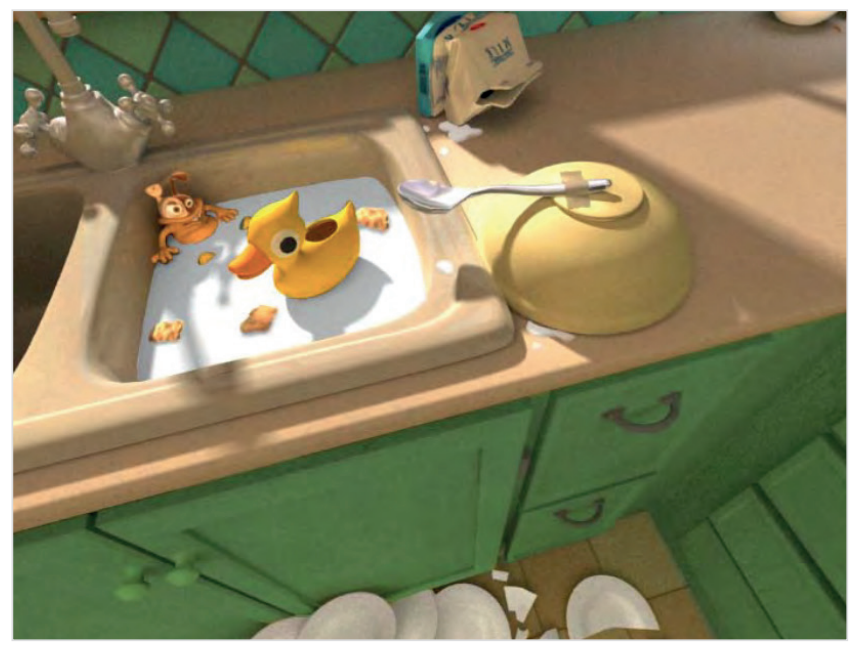

Figura 14. Resultado de la interacción del personaje con el escenario y los elementos de atrezzo 
to un personaje imperfecto le humanizaba y le hacía más atractivo al público infantil: Benito era un personaje consciente de sus limitaciones y se sobreponía a ellas gracias a su descaro y buen humor.

Todos los contenidos ofrecidos en la web podían ser compartidos a través de las redes sociales: Twitter, Tuenti y Facebook. La red social en la que el personaje fue más activo era Facebook que contaba con más de 22.000 me gustas y que se actualizaba casi a diario con contenidos humorísticos siempre vinculados al personaje.

https://www.facebook.com/benitoeldecuetaraflakes

A través de esta plataforma también se proponían concursos a los seguidores y se comunicaban los ganadores. Los comentarios de los seguidores siempre recibían me gustas y respuestas positivas por parte del personaje, que de esta manera animaba a aquellos usuarios especialmente activos en la plataforma.

El canal de YouTube por su parte contaba con más de 700 suscriptores y más de 800.000 visualizaciones. La estrategia transmedia estaba cuidadosamente planificada porque el texto y la manera de presentar al personaje variaba para que el contenido resultara complementario. Al describirlo en el canal de YouTube (BenitosoyBestial), era presentado como un catador de leche, devorador de flakes y jefazo de esta página al que le gusta dormir la siesta, romper muñecos y ver la televisión. El vocabulario básico y las expresiones coloquiales guardaban coherencia en los diferentes medios pero se alteraba el contenido literal que cada uno ofrecía para que el usuario nunca tuviera la impresión de estar ante un argumento repetido.

El principal beneficio obtenido no es económico porque la conexión emocional con el consumidor va mucho más allá del mero acto de consumo

\section{Conclusiones}

Más de una década después de su lanzamiento Benito continuaba siendo un personaje popular hasta tal punto que su éxito en las nuevas plataformas de comunicación motivó un litigio entre la marca y el estudio de animación que en 2016 ha desembocado en una resolución que obligaba a la marca a indemnizar al estudio de animación. El personaje acompañaba al producto en su packaging y tenía otras muchas manifestaciones en redes sociales, apps y spots de televisión. Los mensajes que lanzaba eran sencillos, positivos y transgresores. Benito, siempre con buen humor, acompañaba y facilitaba a los niños el viaje a través de distintas
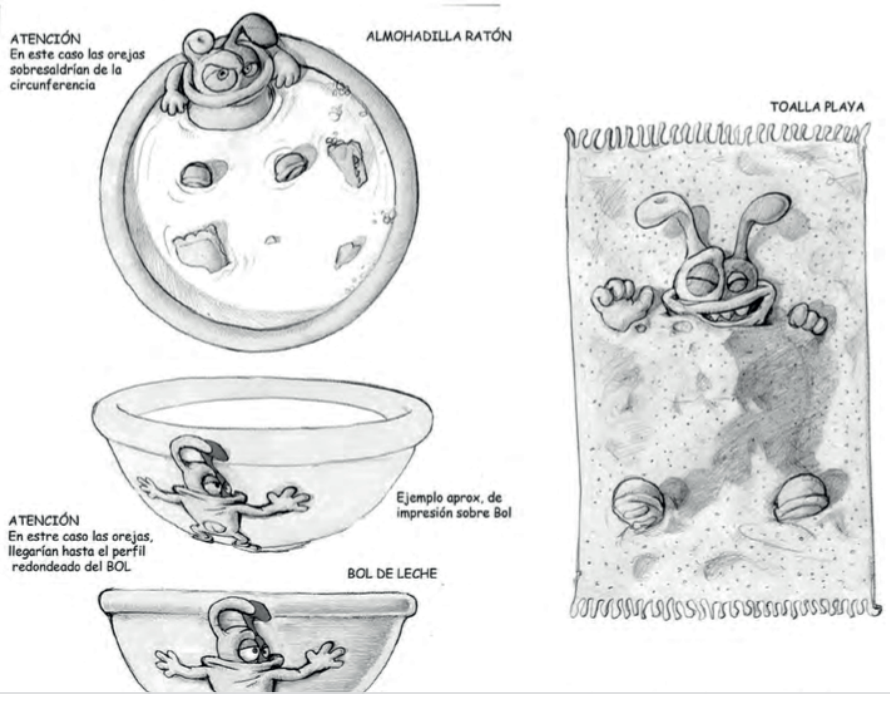

Figura 15. Bocetos de merchandising

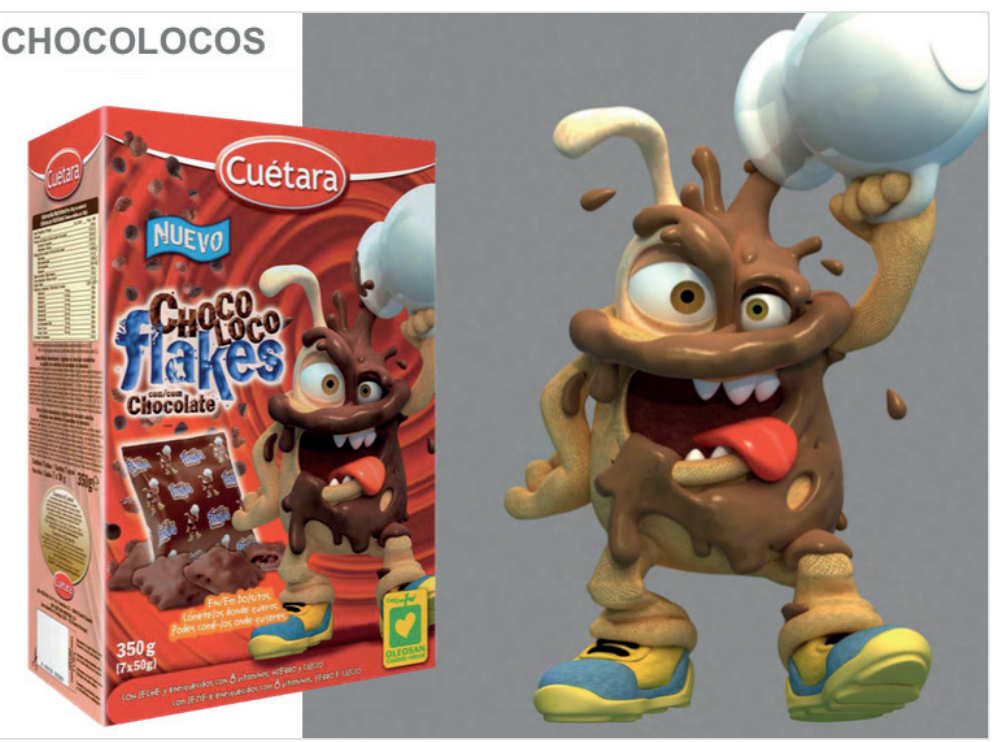

Figura 16. Imagen final del paquete

plataformas: desde el cómic que tenían al alcance mientras desayunaban, pasaban a la app y de allí a las redes sociales donde Benito interpretaba lo cotidiano de forma divertida. En definitiva, Benito dotaba a un hábito de alimentación saludable (como el desayuno) de unos valores relacionados con el humor, la diversión o incluso la lectura.

La creación de un personaje que se identificara con la marca y que fuera conocido por parte del público facilitaba el tránsito a través de los diferentes medios. La eventual conversación entre madre e hija en el desayuno se trasladaba al cómic del envase de cereales que a su vez conducía a una aplicación que remitía a una página de Facebook en la que se ofrecía contenido de actualidad vinculado con el personaje. En todo este trayecto se invitaba a reír, a divertirse jugando y en definitiva a convertir el desayuno en un hábito gratificante gracias, entre otras cosas, al personaje de Benito.

Aplicaciones como Monólogos bestiales, Lanza loros o Bestial kombat ofrecían una experiencia con el personaje que hacían entretenido el desayuno (las aplicaciones se podían consultar 
y descargar en www.soybestial.com). Desde el punto de vista de la comunicacion, el ejemplo de Benito es ilustrativo de cómo funciona el escenario transmedia, la separación entre lo físico y lo digital se desdibuja y los hábitos tradicionales pueden ser gamificados con la ayuda de un personaje y una marca o institución que financie la producción del contenido. Las vías de monetización del producto se diversifican y a los ingresos obtenidos a través de la compra del producto se unen aquellos beneficios que genera el merchandising. Sin embargo, el principal beneficio obtenido a través de este tipo de estrategias no es económico porque la conexión emocional que se establece con el consumidor va mucho más allá del mero acto de consumo y permite mantener una experiencia con la marca que sirve de fundamento para establecer relaciones a medio y largo plazo con el cliente. El producto por tanto, deja de ser un simple cereal y se convierte en una experiencia difícilmente sustituible por cualquier producto de marca blanca.

Por tanto, en un contexto donde las grandes empresas cada vez tienen más difícil mantener sus marcas de calidad en las estanterías de la gran distribución y en el que a su vez los creadores audiovisuales encuentran muchas dificultades para obtener financiación con la que levantar sus proyectos, la vía de unir fuerzas (marcas y creadores) para crear contenidos juntos parece algo más que una opción y abre en definitiva un apasionante campo de trabajo para profesionales e investigadores en comunicación.

\section{Nota}

1. Este artículo se enmarca dentro del proyecto de investigación (P1·1A2014-05), dirigido por el Dr. Javier Marzal-Felici y financiado por la Universitat Jaume I de Castellón y del proyecto de investigación CSO2013-47933-C4: El sistema de investigación en España sobre prácticas sociales de comunicación. Mapa de proyectos, grupos, líneas, objetos de estudio y métodos (MapCom), financiado por el Mineco.

\section{Bibliografía}

Arnau-Roselló, Robert; Galán, Esteban (2013). “La disolución del soporte audiovisual y la quiebra de la linealidad en el relato". Historia y comunicación social, v. 18, pp. 359-367. https://doi.org/10.5209/rev_HICS.2013.v18.44334

Benjamin, Walter (1975). El autor como productor. Madrid: Taurus. ISBN: 9789687943541

Cascajosa, Concepción (2006). "El espejo deformado: una propuesta de análisis del reciclaje en la ficción audiovisual norteamericana". Revista latina de comunicación social, n. 61. http://www.ull.es/publicaciones/latina/200605cascajosa.pdf

Cea-Esteruelas, María-Nereida (2013). “Cybermedia economics: Revenue model and sources of financing". El profesional de la información, v 22. n. 4, pp. 353-361.

https://doi.org/10.3145/epi.2013.jul.12
Costa-Sánchez, Carmen (2014). "El cambio que viene. Audiovisual branded content". Revista Telos. Fundación Telefónica, n. 99, pp. 84-93

https://goo.gl/OYvkC9

Díaz-Noci, Javier; Tous-Rovirosa, Anna (2012). "La audiencia como autor: narrativas transmedia y propiedad intelectual del público. Algunas reflexiones jurídicas". El profesional de la información, v. 21, n. 5 pp. 458-467.

https://doi.org/10.3145/epi.2012.sep.03

Galán, Esteban (2008). Televisión en virtual. Madrid: IORTV. ISBN: 9788488788733

Izquierdo-Castillo, Jéssica (2015). “El nuevo negocio mediático liderado por Netflix: estudio del modelo y proyección en el mercado español". El profesional de la información, v. 24, n. 6. pp. 819-826.

https://doi.org/10.3145/epi.2015.nov.14

Jenkins, Henry (2006). Convergence culture. Where old and new media collide. New York: New York University Press. ISBN: 9780814742815

Manovich, Lev (2001). The language of new media. Cambridge: The MIT Press. ISBN: 0262133741

http://dss-edit.com/plu/Manovich-Lev_The_Language_of_ the_New_Media.pdf

Ryan, Marie-Laure (2004). Narrative across media. The languages of storytelling. Lincoln; London: University of $\mathrm{Ne}-$ braska Press. ISBN: 9780803289932

Scolari, Carlos (2013). "Narrativas transmedia, McLuhan y el discurso científico". Cccblab. Investigación e innovación en cultura, 15 de enero.

http://blogs.cccb.org/lab/es/article_narratives-transmediamcluhan-i-el-discurs-cientific 